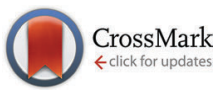

Cite this: Phys. Chem. Chem. Phys., 2016, 18, 10097

Received 5th February 2016, Accepted 10th March 2016

DOI: $10.1039 / c 6 c p 00816 j$

www.rsc.org/pccp

\title{
Silane-initiated nucleation in chemically active plasmas: validation of density functionals, mechanisms, and pressure-dependent variational transition state calculations $\dagger$
}

\author{
Junwei Lucas Bao and Donald G. Truhlar*
}

\begin{abstract}
The growth of anionic silicon hydride clusters is a critically important process in nanodusty plasmas. In the current study, we focus on the formation of homologs of silylene $\left(\mathrm{Si}_{n+1} \mathrm{H}_{2 n+2}, n=3,4\right)$ and $\operatorname{silyl}\left(\mathrm{Si}_{n} \mathrm{H}_{2 n+1}{ }^{-}\right.$, $n=4,5)$ anions via anion-neutral reaction pathways. Species like silyl or silylene anions and their related elementary reactions, which are involved in the formation of silicon hydride clusters, were not used in developing exchange-correlation $(x c)$ density functionals (i.e., they were not included in the training set of semiempirical density functionals); therefore, we explored the accuracy of various widely used xc density functionals based on reaction energies and barrier heights. Among the 21 density functionals we tested, M06-2X has the best performance for a hybrid functional, and MN15-L has the best performance for a local functional. Thermal rate constants of the elementary reactions involved in the reaction mechanism are calculated using M06-2X and multistructural canonical variational transition state theory with the small-curvature tunneling approximation (MS-CVT/SCT). The pressure dependence of unimolecular isomerization reactions is treated with systemspecific quantum RRK theory (SS-QRRK) and the Lindemann-Hinshelwood mechanism.
\end{abstract}

\section{Introduction}

The growth of nanoparticles in nanodusty plasmas is an active research field in plasma physics, chemistry, and engineering. Many physical and chemical processes are involved in the formation of nanoparticles in chemically active plasmas, including nucleation, isomerization, electron capture and ionization, and mass and momentum transport. Anion-neutral reactions are one of the major chemical reactions in silicon hydride clustering in silanecontaining reactive plasmas. ${ }^{1,2}$ Rate constants of anion-neutral reactions are used in building transport equations or boundary conditions in many simulation studies for investigating the distribution of the sizes of nanoparticles and their population in a plasma. ${ }^{3-7}$ However, due to the complexity of the systems and the unusual conditions of the chemical reactions (i.e., plasma), accurate experimental measurements for these anion-neutral reactions are very difficult and hence are scarce. The majority of

Department of Chemistry, Chemical Theory Center, and Minnesota Supercomputing Institute, University of Minnesota, Minneapolis, Minnesota 55455-0431, USA.

E-mail: truhlar@umn.edu

$\dagger$ Electronic supplementary information (ESI) available: Classical forward barriers and energy of reactions; mean unsigned errors (MUEs) computed by various model chemistries; reaction symmetry numbers; MS-T factors of activation for reverse reactions; MS-CVT/SCT rate constants for reverse reactions; fitting parameters for MS-CVT/SCT rate constants of reverse reactions; activation energies. See DOI: $10.1039 / \mathrm{c} 6 \mathrm{cp} 00816 \mathrm{j}$ the reaction rates needed for modeling nanodusty plasmas are empirically estimated, and Agarwal and Girshick ${ }^{8}$ noted that "there is considerable uncertainty in the values of rate constants for anion-neutral reactions that are primarily responsible for clustering in this system, and thus any correction factor one might apply for the predicted nucleation rate would itself be highly uncertain". Theoretical calculations of chemical structures, energetics, and thermal rate constants can play an important role in reducing the uncertainty involved in plasma modeling. Although fast empirical methods for estimating thermodynamic functions and rate constants exist, ${ }^{9}$ we do not use such approach in the current work; thermodynamic functions and thermal rate constants reported in this work are computed from $a b$ initio calculations.

Silyl anion $\left(\mathrm{Si}_{n} \mathrm{H}_{2 n+1}{ }^{-}\right)$reactions with silane and silylene anion $\left(\mathrm{Si}_{n+1} \mathrm{H}_{2 n+2}{ }^{-}\right)$reactions with silane are the dominant anionic pathways for the formation of nanoparticles in plasmas. Higher homologs of silicon hydrides with branched chains are generated in these reactions, which proceed with the elimination of molecular hydrogen. The silicon hydrides formed via silyl anion-silane reactions are $\mathrm{H}_{3} \mathrm{SiH}_{2} \mathrm{Si}^{-} \rightarrow\left(\mathrm{H}_{3} \mathrm{Si}\right)_{2} \mathrm{HSi}^{-} \rightarrow$ $\left(\mathrm{H}_{3} \mathrm{Si}\right)_{3} \mathrm{Si}^{-} \rightarrow\left(\mathrm{H}_{3} \mathrm{Si}\right)_{3} \mathrm{SiH}_{2} \mathrm{Si}^{-}$, where ":" represents paired electrons on the terminal $\mathrm{Si}$ atom; the silicon hydrides formed via silylene anion-silane reactions are $\mathrm{H}_{3} \mathrm{SiHSi}^{\bullet-} \rightarrow \mathrm{H}_{3} \mathrm{SiH}_{2} \mathrm{SiHSi}^{\bullet-} \rightarrow$ $\left(\mathrm{H}_{3} \mathrm{Si}\right)_{2} \mathrm{HSiHSi}^{\bullet-} \rightarrow\left(\mathrm{H}_{3} \mathrm{Si}\right)_{3} \mathrm{SiHSi}^{\bullet-}$, where “ø”, represents an unpaired electron on the terminal $\mathrm{Si}$ atom. 
In the present study, we focus on clusters that contain no more than five silicon atoms. The chemical mechanism of the initial step of the clustering process, i.e., the formation of $\left(\mathrm{H}_{3} \mathrm{Si}\right)_{2} \mathrm{HSi}$ : and $\mathrm{H}_{3} \mathrm{SiH}_{2} \mathrm{SiHSi}^{\bullet-}$, has been investigated in a previous work. ${ }^{10} \mathrm{In}$ the current work, since the studied kind of system is not represented in the training set of any density functional known to us, we carry out benchmark tests for various density functionals, and this provides an opportunity to investigate the transferability of various semiempirical exchange-correlation functionals. Chemical structures, energetics, and thermal rate constants in the mechanisms are computed using the best functional among the functionals we tested in this work.

Two unimolecular isomerization reactions are involved in the reaction mechanism we propose in this work, and the pressure dependences of their thermal rate constants are estimated using system-specific quantum Rice-Ramsperger-Kassel (SS-QRRK) theory combined with the Lindemann-Hinshelwood thermal activation mechanism. The SS-QRRK method was proposed recently ${ }^{11}$ as a convenient way to use variational transition state theory to treat pressure dependences of chemical reaction rates, and it was applied to a chemical activation mechanism; the present article is the first application to a thermally activated unimolecular reaction. For a chemically activated unimolecular reaction, the low-pressure rate constants of the formation of the stabilized adduct are lower than the high-pressure-limit, and the rate constants of the further isomerization/dissociation of the formed adduct are larger than the high-pressure equilibrium rate constant; and in thermally activated unimolecular reactions, the low-pressure rate constants are smaller than the high-pressure equilibrium rate constant, and hence the pressure effect for this kind of reaction is called "falloff."

\section{Theoretical background}

\subsection{High-pressure-limit thermal rate constants}

High-pressure-limit thermal rate constants are computed using multi-structural canonical variational transition state theory with the small-curvature tunneling approximation (MS-CVT/SCT) as follows: ${ }^{12-15}$

$$
k^{\mathrm{MS}-\mathrm{CVT} / \mathrm{SCT}}=F_{\mathrm{act}} \kappa_{1}^{\mathrm{SCT}} \Gamma_{1}^{\mathrm{CVT}} k_{1}^{\mathrm{TST}}
$$

where $F_{\text {act }}$ is multi-structural torsional potential anharmonicity factor of activation ${ }^{16,17}$ computed by MS-T(C) method; ${ }^{18} \kappa_{1}^{\mathrm{SCT}}$ is a small-curvature tunneling transmission coefficient for the lowest-energy conformer of the transition state, $\Gamma_{1}^{\mathrm{CVT}}$ is CVT variational transmission coefficient for the lowest-energy path, and $k_{1}^{\mathrm{TST}}$ is the conventional transition state theory rate constant computed based on the lowest-energy path:

$$
k_{1}^{\mathrm{TST}}=\left\{\begin{array}{cc}
\sigma_{\mathrm{rxn}} \frac{k_{\mathrm{B}} T}{h} \frac{Q^{\ddagger}}{Q^{\mathrm{R}}} \mathrm{e}^{-V^{\ddagger} / k_{\mathrm{B}} T} & \text { unimolecular reaction } \\
\sigma_{\mathrm{r} \times n} \frac{k_{\mathrm{B}} T}{h} \frac{Q^{\ddagger}}{\Phi^{\mathrm{R}}} \mathrm{e}^{-V^{\ddagger} / k_{\mathrm{B}} T} & \text { bimolecular reaction }
\end{array}\right.
$$

where $Q^{\ddagger}$ and $Q^{\mathrm{R}}$ are rigid-rotor-harmonic-oscillator partition functions for the transition state structure and reactant; $\Phi^{\mathrm{R}}$ is the reactants partition function per unit volume. $V^{\ddagger}$ is the barrier height, $k_{\mathrm{B}}$ is the Boltzmann constant, $h$ is Planck's constant, and $T$ is absolute temperature. Expressing the TST rate constant in the form of eqn (2), the rotational partition function does not contain rotational symmetry number; the rotational symmetry number is included in the reaction symmetry number $\sigma_{\mathrm{rxn}}$ as follows: ${ }^{19}$

$$
\sigma_{\text {rxn }}= \begin{cases}\sigma^{\mathrm{R}} / \sigma^{\ddagger} & \text { unimolecular reaction } \\ \sigma^{\mathrm{R} 1} \sigma^{\mathrm{R} 2} / \sigma^{\ddagger} & \text { bimolecular reaction }\end{cases}
$$

where $\sigma^{\mathrm{R}}$ and $\sigma^{\ddagger}$ are the rotational symmetry number for the reactant and transition state structure, which are equal to the order of the rotational subgroup for polyatomic molecule; rotational symmetry number is 1 for heteronuclear diatomic molecule and 2 for homonuclear diatomic molecule. The reaction symmetry number we used here excludes the non-superimposable mirror-image conformers; the contributions from these mirrorimage conformers are treated within MS-T method. However, the contributions from enantiomers should be included in the reaction symmetry number or the rotational partition function if the MS-T method is not applied. ${ }^{19,20}$ The reaction symmetry numbers for forward and reverse reactions involved in the current study are tabulated in the ESI. $\dagger$

\subsection{System-specific quantum RRK theory with Lindemann- Hinshelwood theory}

In this section, we consider the effect of pressure on the unimolecular reactions by using SS-QRRK theory ${ }^{11}$ with the Lindemann-Hinshelwood mechanism.

For a unimolecular reaction, the following LindemannHinshelwood thermal activation mechanism is considered: ${ }^{21}$

$$
\begin{aligned}
& \mathrm{A}(T)+\mathrm{M} \underset{k_{\mathrm{c}}(T)}{\stackrel{k_{1}(E ; T)}{\rightleftarrows}} \mathrm{A}^{*}(E)+\mathrm{M} \quad \text { step } 1 \\
& \mathrm{~A}^{*}(E) \stackrel{k_{2}(E)}{\longrightarrow} \mathrm{P} \quad \text { step } 2
\end{aligned}
$$

where $\mathrm{A}(T)$ represents the thermally equilibrated reactant at temperature $T ; \mathbf{M}$ is the bath gas; $\mathrm{A}^{*}(E)$ is the rovibrationally excited molecule with total rovibrational energy $E$; and $\mathrm{P}$ is the isomerization product. This mechanism includes the RRK assumption that energy in $\mathrm{A}^{*}$ is rapidly statistically redistributed among modes subject only to the constraint of total energy $E$ so that the reactivity of $\mathrm{A}^{*}$ is simply a function of total energy. The rate constant of energization is $k_{1}$, and the rate constant of isomerization is $k_{2}$, and by the RRK assumption both of these rate constants depend on the total energy of $\mathrm{A}^{*}$; and $k_{1}$ also depends parametrically on temperature $T$. The rate constant of de-energization is $k_{\mathrm{c}}$ and is treated as temperaturedependent but energy-independent, which is the strong collision assumption. However the strong-collision assumption is mitigated in the present work by computing $k_{\mathrm{c}}$ as the product of the Lennard-Jones collision rate constant and a collision efficiency factor $\beta_{\mathrm{c}}$, where the latter is computed by using Troe's modified collision model. ${ }^{22,23}$ 
The pressure-dependent unimolecular reaction rate constant $k_{\text {uni }}(T, p)$ for the above mechanism is: ${ }^{24-26}$

$$
k_{\text {uni }}(T, p)=\int_{E=E_{0}}^{\infty} \mathrm{d} E \frac{K(E, T) k_{2}(E)}{1+\frac{k_{2}(E)}{k_{\mathrm{c}}(T)[\mathrm{M}]}}
$$

where $K(E, T)$ is the equilibrium constant of the first step, $[\mathrm{M}]$ is the concentration of bath gas, $p$ is pressure, and $E_{0}$ is the threshold energy. Note that $K(E, T)$ is mixed-ensemble equilibrium constant, representing the thermal equilibrium of species $\mathrm{A}^{*}$ in a microcanonical ensemble at energy $E$ with species A in a thermal ensemble with temperature $T$. Therefore,

$$
K(E, T)=\frac{\rho(E) \exp (-E / R T)}{\int_{0}^{\infty} \mathrm{d} E^{\prime} \rho\left(E^{\prime}\right) \exp \left(-E^{\prime} / R T\right)}=\frac{\rho(E) \exp (-E / R T)}{Q^{\mathrm{A}}(T)}
$$

where $\rho(E)$ is the density of states, and $Q^{\mathrm{A}}(T)$ is the rovibrational partition function of $A$.

In QRRK theory, ${ }^{24,27}$ one models the states of A and $\mathrm{A}^{*}$ as the discrete states of a system with $s$ uncoupled harmonic oscillator modes, each with frequency $\bar{\omega}$ in wave numbers $\left(e . g ., \mathrm{cm}^{-1}\right)$. Then the integrals over $E$ are replaced by sums over $n$, where $n$ is the number of quanta excited at energy $E(n=E / h c \bar{\omega}$, where the zero of energy is the potential energy of the equilibrium structure of A). With this model and with [M] given by the ideal gas law, eqn (4) can be written as:

$$
k_{\text {uni }}(T, p)=\sum_{n=m}^{+\infty} \frac{k_{2}(E=n h c \bar{\omega}) K(n, T)}{1+\frac{k_{2}(E=n h c \bar{\omega})}{k_{\mathrm{c}}(T)} \cdot \frac{R T}{p}}
$$

where

$$
\begin{gathered}
K(n, T)=\exp \left(\frac{-n h c \bar{\omega}}{k_{\mathrm{B}} T}\right)\left[1-\exp \left(\frac{-h c \bar{\omega}}{k_{\mathrm{B}} T}\right)\right]^{s} \frac{(n+s-1) !}{n !(s-1) !} \\
m=E_{0} / h c \bar{\omega}
\end{gathered}
$$

and $R$ is ideal gas constant, and $c$ is the speed of light. Notice that in the limit of $p \rightarrow \infty$, the high-pressure-limit unimolecular rate constant is recovered in eqn (4) and (6), and in the lowpressure limit, the unimolecular rate "constant" is no longer a constant (i.e., no longer independent of concentrations), but rather is proportional to $[\mathrm{M}]$ or $p$.

In SS-QRRK, we use eqn (6)-(8) with $\bar{\omega}$ taken as the geometric mean of the $s$ vibrational frequencies of A (where $s$ is $3 N-6$, and $N$ is the number of atoms in A), and with $E_{0}$ and the microcanonical isomerization rate constant $k_{2}(E)$ parameterized by using QRRK theory calibrated to match the MS-CVT/SCT canonical rate constant at high pressure. In QRRK theory, the microcanonical rate constant is a frequency factor $A$ (with units of reciprocal time) times the probability that a molecule with $n$ quanta of vibrational theory has at least $m$ quanta in one of the modes (the reactive mode), where $m$ is given in terms of the threshold energy by eqn (8). This yields ${ }^{24}$

$$
k_{2}^{\mathrm{QRRK}}(E=n h c \bar{\omega})=A \frac{n !(n-m+s-1) !}{(n-m) !(n+s-1) !}
$$

Substituting this into eqn (6), carrying out the sum, and taking the limit of $p \rightarrow \infty$ yields the Arrhenius form: ${ }^{19,24}$

$$
k_{\mathrm{uni}}^{\mathrm{QRRK}}(T, p=\infty)=A \exp (-m h c \bar{\omega} / R T)
$$

Thus, to parameterize QRRK theory, the parameter $m$ is calculated from the MS-CVT/SCT Arrhenius activation energy $E_{\mathrm{a}}^{\mathrm{MS}-\mathrm{CVT} / \mathrm{SCT}}(T)$ :

$$
\begin{gathered}
m(T)=\frac{E_{0}(T)}{h c \bar{\omega}} \\
E_{0}(T)=E_{\mathrm{a}}^{\mathrm{MS}-\mathrm{CVT} / \mathrm{SCT}}(T)=-R \frac{\mathrm{d} \ln k^{\mathrm{MS}-\mathrm{CVT} / \mathrm{SCT}}(T)}{\mathrm{d}(1 / T)}
\end{gathered}
$$

and the frequency factor $A$ in QRRK theory is set equal the MSCVT/SCT Arrhenius pre-exponential factor, i.e.,

$$
A(T)=k^{\mathrm{MS}-\mathrm{CVT} / \mathrm{SCT}}(T) \exp \left[E_{\mathrm{a}}^{\mathrm{MS}-\mathrm{CVT} / \mathrm{SCT}}(T) / R T\right]
$$

Note that both $E_{0}$ and $A$ depend on temperature in the parameterized rate expression. Therefore $k_{2}(E)$ in eqn (6) becomes $k_{2}(E, T)$ given by eqn (9) and (11)-(13). The sum in eqn (6) is evaluated with a step size of one quantum, and the factorials therefore all have non-integer arguments and are evaluated using gamma functions.

The de-energization rate constant is modeled as in our previous work, ${ }^{11}$ using empirical Lennard-Jones parameters, the average energy transferred, and the energy dependence factor $F_{\mathrm{E}}$ of the density of states (which is the thermal population of unimolecular states above the threshold energy of the reactant normalized by a density of states factor at the threshold energy); these quantities are given in Section 3.4.

\section{Computational details}

\subsection{Electronic structure calculations}

Initial geometries of the reactants, products, and transition state structures are optimized with the M08-HX functional ${ }^{28}$ and the MG3S basis ${ }^{29}$ for benchmark studies; tight convergence criteria are used for both the SCF calculations and the geometry optimizations. For silicon atoms, the MG3S basis is equivalent to the $6-311+\mathrm{G}(3 \mathrm{~d} 2 \mathrm{f})$ basis, and for hydrogen atoms it is equivalent to the $311 \mathrm{G}(2 \mathrm{p})$ basis. $^{30-32}$ All the density functional integrations are carried out with a grid of 99 radial shells around each atom and 974 angular points per shell. ${ }^{33}$ All the electronic structure calculations are performed with a locally modified version of the Gaussian 09 software. ${ }^{34,35}$

In order to test the accuracy of various popular density functionals for silyl or silylene anions reactions, a benchmark study was carried out based on classical barrier heights and classical energies of reactions (these are relative Born-Oppenheimer potential energies at stationary points and are exclusive of zero-point or thermal vibrational energy). Five reactions 
Table 1 Reactions used in benchmark study

\begin{tabular}{lll}
\hline & Chemical equation & Reaction type \\
\hline R1 & $\mathrm{SiH}_{3} \mathrm{SiHSiH}_{2}{ }^{-}+\mathrm{SiH}_{4} \rightarrow\left(\mathrm{SiH}_{3}\right)_{2} \mathrm{SiHSiH}_{2}{ }^{-}+\mathrm{H}$ & Nucleophilic reaction \\
$\mathrm{R} 2$ & $\left(\mathrm{SiH}_{3}\right)_{2} \mathrm{SiHSiH}_{2}{ }^{-}+\mathrm{H} \rightarrow\left(\mathrm{SiH}_{3}\right)_{2} \mathrm{SiHSiH}^{-}+\mathrm{H}_{2}$ & Hydrogen $(\mathrm{H})$ abstraction \\
$\mathrm{R} 3$ & $\left(\mathrm{SiH}_{3}\right)_{2} \mathrm{SiH}^{-}+\mathrm{SiH}_{4} \rightarrow\left(\mathrm{SiH}_{3}\right)_{2} \mathrm{SiH}_{2}+\mathrm{SiH}_{3}{ }^{-}$ & Hydrogen $(\mathrm{H})$ abstraction \\
$\mathrm{R} 4$ & $\left(\mathrm{SiH}_{3}\right)_{2} \mathrm{SiH}_{2}+\mathrm{SiH}_{3}{ }^{-} \rightarrow\left(\mathrm{SiH}_{3}\right)_{2} \mathrm{SiHSiH}_{2}{ }^{-}+\mathrm{H}_{2}$ & Hydrogen $\left(\mathrm{H}_{2}\right)$ elimination \\
R5 & $\left(\mathrm{SiH}_{3}\right)_{2} \mathrm{SiHSiH}_{2}{ }^{-} \rightarrow\left(\mathrm{SiH}_{3}\right)_{2} \mathrm{SiSiH}_{3}{ }^{-}$ & Intramolecular hydrogen migration \\
\hline
\end{tabular}

Table 2 Exchange-correlation functionals tested in the current work and their percentage of non-local Hartree-Fock exchange (\% X)

\begin{tabular}{lcllll}
\hline Functional & $\% X$ & xcF & $\% X$ & xcF & $\% X$ \\
\hline M11-L & 0 & (BB97X-D & $22.2-100^{a}$ & SOGGA11-X & 35.42 \\
MN12-L & 0 & HSE06 & $25-0^{b}$ & MPW1K & 42.8 \\
MN15-L & 0 & MN12-SX & $25-0^{b}$ & M11 & $42.8-100^{a}$ \\
MGGAMS2h & 9 & PBE0 & 25 & M08-HX & 52.23 \\
TPSSh & 10 & B97-3 & 26.93 & M06-2X & 54 \\
$\tau$ HCTHhyb & 15 & M06 & 27 & M05-2X & 56 \\
B3LYP & 20 & M05 & 28 & M08-SO & 56.79
\end{tabular}

${ }^{a}$ The percentage of Hartree-Fock exchange increases from the first value listed for small interelectronic separation to $100 \%$ at large interelectronic separation. ${ }^{b}$ The percentage of Hartree-Fock exchange decreases from $25 \%$ at small interelectronic separation to 0 at large interelectronic separation.

(as summarized in Table 1) were selected from our proposed reaction mechanisms for use in the benchmark study.

Single-point energy calculations are performed based on M08-HX/MG3S geometries using various density functionals (tabulated in Table 2) combined with the MG3S, jun-cc-pVTZ ${ }^{36}$ and jul-cc-pVTZ ${ }^{37}$ basis sets. Density functionals tested in the current work includes three local functionals (M11-L, ${ }^{38}$ MN12-L, ${ }^{39}$ and MN15- ${ }^{40}$ ) and 18 hybrid functionals (B3LYP, ${ }^{41}$ PBE0, ${ }^{42}$ TPSSh, ${ }^{43}$ MGGA_MS2h, ${ }^{44}$ MPW1K, ${ }^{45}$ M05, ${ }^{46}$ M06, ${ }^{47}$ M05-2X, ${ }^{48}$ M06-2X, ${ }^{47}$ M08-HX, ${ }^{28}$ M08-SO, ${ }^{28}$ M11, ${ }^{49}$ MN12-SX, ${ }^{50}$ SOGGA11-X, ${ }^{51}$ B97-3, ${ }^{52}$ HSE06, ${ }^{53}$ นHCTHhyb, ${ }^{54}$ and $\omega \mathrm{B} 97 \mathrm{X}-\mathrm{D}^{55}$ ).

The reference energy values are computed by $\operatorname{CCSD}(\mathrm{T})^{56} /$ CBS, where the complete basis set (CBS) limit is obtained by the following strategy: ${ }^{57}$

$$
E_{\mathrm{CBS}}^{\mathrm{CCSD}(\mathrm{T})}=E_{\mathrm{CBS}}^{\mathrm{MP} 2}+\left(E_{\mathrm{SBS}}^{\mathrm{CCSD}(\mathrm{T})}-E_{\mathrm{SBS}}^{\mathrm{MP} 2}\right)
$$

where SBS means the small basis set (which is aug-cc-pVTZ ${ }^{37,58}$ in the current work), and the MP2 $2^{59} / \mathrm{CBS}$ energy is computed by respectively extrapolating the Hartree-Fock (HF) exchange energy and MP2 correlation energy as follows: ${ }^{60-64}$

$$
\begin{gathered}
E_{\mathrm{CBS}}^{\mathrm{HF}}=\frac{E_{X-1}^{\mathrm{HF}}-\lambda E_{X}^{\mathrm{HF}}}{1-\lambda} \\
E_{\mathrm{CBS}}^{\mathrm{corr}}=\frac{X^{3} E_{X}^{\mathrm{corr}}-(X-1)^{3} E_{X-1}^{\mathrm{corr}}}{X^{3}-(X-1)^{3}}
\end{gathered}
$$

where

$$
\lambda=\frac{X}{X+1} \exp [9(\sqrt{X}-\sqrt{X-1})]
$$

In the above equations, we use $X=4$ (which is taken as aug-ccpVQZ) and $X-1=3$ (which is taken as aug-cc-pVTZ). Finally,

$$
E_{\mathrm{CBS}}^{\mathrm{MP} 2}=E_{\mathrm{CBS}}^{\mathrm{HF}}+E_{\mathrm{CBS}}^{\mathrm{corr}}
$$

\subsection{Direct dynamics calculations}

For the direct dynamics calculations, all the species are re-optimized by M06-2X/MG3S, which was selected as the level for direct dynamics calculations based on the benchmark tests (as will be discussed in Section 4.1).

Canonical variational transition state theory calculations with the small-curvature tunneling approximation were carried out in non-redundant internal coordinates ${ }^{65,66}$ with a step size of $0.002 a_{0}$ (note: $1 a_{0}=1 \mathrm{bohr}=0.5292 \AA$ ). The minimum energy paths (MEPs) are computed using Page-McIver algorithm ${ }^{67}$ from -2.0 to $+2.0 a_{0}$. The RODS algorithm ${ }^{68}$ was used to re-orient the generalized-transition-state-theory dividing surface. A scaling factor $0.970^{69}$ was used to scale all the vibrational frequencies in the generalized normal mode calculations.

For bimolecular reactions with a negative barrier, the smallcurvature tunneling transmission coefficient was computed using the ion-dipole complex as the initial state; the final bimolecular reaction rate constant is the product of the so-obtained tunneling transmission coefficient with the bimolecular reaction rate constant computed without tunneling. This is consistent with the fact that the tunneling calculation is performed for the high-pressure limit where the ion-dipole complex is fully thermalized (the issue of tunneling from the states of the precursor complex at lower energies than the bimolecular reactant ground state is discussed elsewhere ${ }^{70,71}$ ). Multi-structural torsional anharmonicity (MS-T) rovibrational partition functions were computed using the MSTor program; ${ }^{72}$ VTST calculations were performed with the Polyrate ${ }^{73}$ and Gaussrate $^{74}$ programs.

\subsection{Torsional anharmonicity}

The multi-structural torsional anharmonicity (MS-T) rovibrational partition functions are computed based on coupled effective torsional potentials. The local periodicities of $-\mathrm{SiH}_{3}$ groups are set to be 3 . The MS-T partition functions include the contributions from all the distinguishable conformational structures including non-superimposable mirror images.

\subsection{Parameters used in de-energization}

In the current study, Ar gas, which is commonly used in chemical vapor decomposition ${ }^{75}$ (CVD) and in studying nucleation processes in plasmas, ${ }^{8}$ is selected as the bath gas used in estimation of the pressure-dependent rate constants of the unimolecular isomerization reactions. Lennard-Jones parameters $\varepsilon / k_{\mathrm{B}}$ and $\sigma$ are taken for Ar as $120 \mathrm{~K}$ and $3.4 \AA^{76}$ and for $\mathrm{Si}_{4} \mathrm{H}_{n}$ species as $254 \mathrm{~K}$ and $5.8 \AA$, as used in previous silane plasma modeling. ${ }^{77}$ 
The energy transfer parameter $\langle\Delta E\rangle$, which is the average energy transferred during both energization and de-energization processes and which is used for computing the collision efficiency factor, is chosen to be $740 \mathrm{cal} \mathrm{mol}^{-1}$; this value has been used previously for modeling $\mathrm{SiH}_{4}$ colliding with $\mathrm{Ar}^{78}$ The Si clusters we considered in the current work are larger than $\mathrm{SiH}_{4}$, and therefore one might hypothesize that a larger energy transfer parameter $\langle\Delta E\rangle$ should be used. To test this, we repeated the calculations for reaction $\mathrm{RB}$, step 1 with a doubled energy transfer parameter of $1480 \mathrm{cal} \mathrm{mol}^{-1}$, and we found that the obtained falloff curves (shown in Fig. S2 in ESI $\dagger$ ) are not sensitive to this change. Doubling the energy transfer parameter leads to larger $k(p)$ values (i.e., stronger collisions and smaller falloff effect) and at most a factor of 2 difference. (The maximum effect is at $1500 \mathrm{~K}, 0.001$ bar.) The collision parameters and energy transfer parameters, in principle, could be determined from theoretical trajectory calculations; ${ }^{79}$ we do not use such approach in the current work based on computational cost and the desire for a simple method that can be widely used in mechanism development.

The energy dependence factor $F_{E}$ of the density of states can be directly computed using Troe's definition: ${ }^{22}$

$$
F_{E}=\frac{\int_{E_{0}}^{+\infty} \rho(E) \mathrm{e}^{-E / k_{\mathrm{B}} T} \mathrm{~d} E}{k_{\mathrm{B}} T \rho\left(E_{0}\right) \mathrm{e}^{-E_{0} / k_{\mathrm{B}} T}}
$$

with density of states computed from MS-T partition function by inverse Laplace transform; alternatively, $F_{E}$ can be computed by the empirical Whitten-Rabinovitch approximation using eqn (6) and (8) in Troe's work. ${ }^{80} F_{E}$ is used to compute the collision efficiency coefficient $\beta_{\mathrm{c}}$ using the following equation:

$$
\frac{\beta_{\mathrm{c}}}{1-\beta_{\mathrm{c}}{ }^{1 / 2}}=\frac{|\langle\Delta E\rangle|}{F_{E} k_{\mathrm{B}} T}
$$

For falloff calculations on $\left(\mathrm{SiH}_{3}\right)_{2} \mathrm{SiHSiH}^{-}$, we used $F_{E}$ values computed from MS-T partition function in eqn (19) which yields $1.55,1.84$, and 2.85 at $298 \mathrm{~K}, 400 \mathrm{~K}$, and $600 \mathrm{~K}$, respectively, for comparison, $F_{E}$ values computed using Whitten-Rabinovitch approximation at $298 \mathrm{~K}, 400 \mathrm{~K}$, and $600 \mathrm{~K}$ are $1.43,1.63$, and 2.30 , which agree with the values we used within 8,11 , and $19 \%$, respectively. The $F_{E}$ values computed from MS-T partition function for $\left(\mathrm{SiH}_{3}\right)_{2} \mathrm{SiHSiH}_{2}{ }^{-}$are 1.60, 1.97 , and 3.32 at $298 \mathrm{~K}, 400 \mathrm{~K}$, and $600 \mathrm{~K}$, respectively, and they are used in falloff calculations of RC step 3. The corresponding $F_{E}$ values computed by the Whitten-Rabinovitch approximation at $298 \mathrm{~K}, 400 \mathrm{~K}$, and $600 \mathrm{~K}$ are $1.45,1.71$, and 2.51 , which agree with the values we used within 9, 13, and $24 \%$, respectively.

\section{Results and discussion}

\subsection{Benchmark of various density functionals}

Although coupled cluster theory with single and double excitations and quasi-perturbative connected triple excitations, i.e., $\operatorname{CCSD}(\mathrm{T})$, is often viewed as the gold standard in quantum chemistry, it uses a single configuration state function as the reference wave function (i.e., it is a "single-reference" method), and therefore it might not be appropriate to use $\operatorname{CCSD}(\mathrm{T})$ as a benchmark for systems with strong multi-reference characters (such as bond dissociation ${ }^{81}$ and transition metal chemistry ${ }^{82}$ ). To ascertain its expected reliability, we computed the $T_{1}$ diagnostic $^{83}$ values for all the species involved in the reactions that are used for benchmark study, since this diagnostic has been proposed as a measure of the suitability of singereference coupled cluster theory. The molecule with the largest $T_{1}$ diagnostic value is the transition state structure of reaction (R1) $\left(\mathrm{Si}_{4} \mathrm{H}_{10}{ }^{-}\right)$, for which the value is 0.0252 computed by $\operatorname{CCSD}(\mathrm{T})$ /aug-cc-pVTZ; this value is much smaller than 0.045 , which has been suggested ${ }^{84-86}$ as a criterion for the applicability of single-reference methods to open-shell molecules, and hence we concluded that $\operatorname{CCSD}(\mathrm{T})$ can serve as a reference for testing other methods in this work.

The mean unsigned errors (MUEs) of various density functionals computed with respect to CCSD(T)/CBS for reactions (R1)-(R5) and the overall MUEs are shown in Fig. 1. MUEs are calculated based on zero-point-vibrational-energy-exclusive forward barrier height and energy of reaction. MUEs shown in Fig. 1 are computed using the MG3S basis; using larger basis sets such as jun-cc-pVTZ and jul-cc-pVTZ has a negligible effect on the MUEs. All the computed classical forward barrier heights, energies of reaction, and MUEs are tabulated in the ESI. $\dagger$

Among the 25 tested density functionals, the global-hybrid meta-GGA functional M06-2X performs the best for all the reactions; the MUEs for reactions (R1)-(R5) and the overall MUE are $0.34,0.35,0.22,0.76,0.95$ and $0.52 \mathrm{kcal} \mathrm{mol}^{-1}$, respectively. They are all better than the value of $1 \mathrm{kcal} \mathrm{mol}^{-1}$,

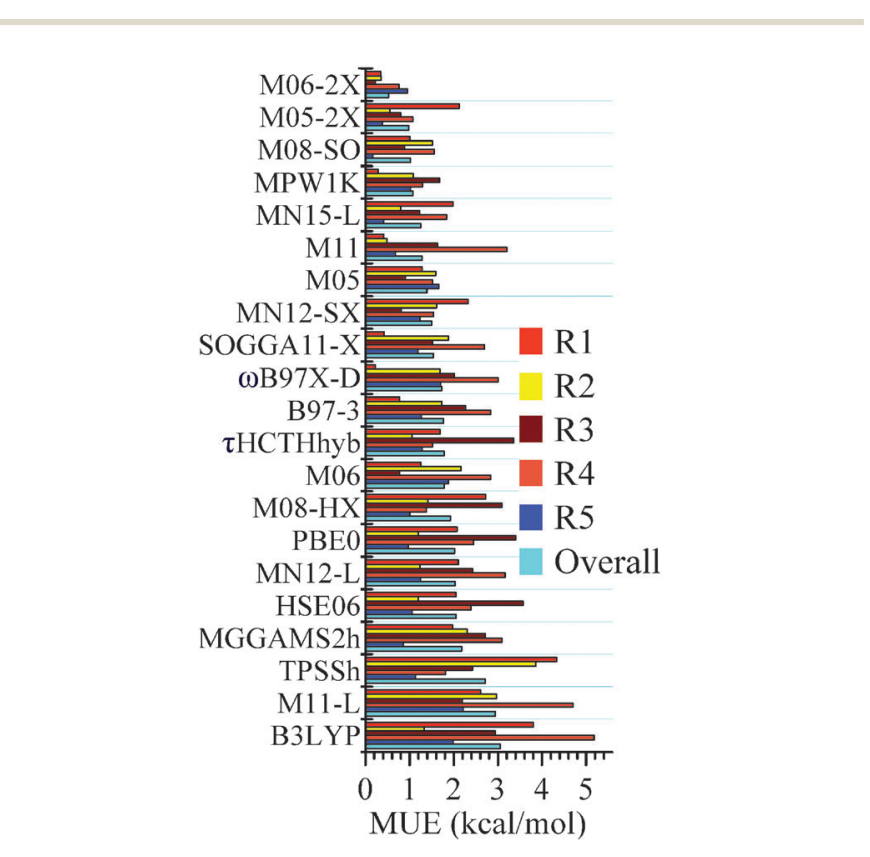

Fig. 1 Mean unsigned errors (MUEs, in $\mathrm{kcal} \mathrm{mol}^{-1}$ ) for reactions (R1)-(R5) and the overall MUEs of various density functionals. MUEs shown in this figure (computed with the MG3S basis) are based on classical forward barrier and energy of reaction; CCSD(T)/CBS values are used as references. The functionals are in order of increasing overall MUE. 
which is usually quoted as "chemical accuracy". M06-2X, M05-2X, M08-SO, and MPW1K are the four best performing functionals and all have overall MUEs within the chemical accuracy criterion. Among the three tested local density functionals (M11-L, MN12-L and MN15-L), MN15-L possesses the smallest overall MUE, which is $1.25 \mathrm{kcal} \mathrm{mol}^{-1}$; it is encouraging that this surpasses the accuracy of many popular hybrid density functionals (such as B3LYP and $\omega$ B97X-D) and the recently developed MGGA_MS2h. This is encouraging for the very new MN15-L functional since there is no silyl or silylenerelated species in its training set and since local functionals are usually less accurate than hybrid functionals for reaction energies and barrier heights.

Note that the density functional calculations converge more rapidly with respect to basis set than $\operatorname{CCSD}(\mathrm{T})$, and so $\operatorname{CBS}$ extrapolations were not needed. A great advantage of density functional theory in this respect is that the reaction path calculations and the required Hessians along the reaction path are affordable even with the reasonably well-converged MG3S basis set.

\subsection{Proposed reaction mechanisms}

In this work, we consider the silicon hydride clusters formed from silylene or silyl anions reactions with silane that involve no more than 5 silicon atoms. To be more specific, the composite reactions we studied are:

$$
\begin{aligned}
& (\mathrm{RA}): \mathrm{SiH}_{3} \mathrm{SiHSiH}_{2}{ }^{-}+\mathrm{SiH}_{4} \rightarrow\left(\mathrm{SiH}_{3}\right)_{2} \mathrm{SiHSiH}^{-}+\mathrm{H}_{2} \\
& (\mathrm{RB}):\left(\mathrm{SiH}_{3}\right)_{2} \mathrm{SiHSiH}^{-}+\mathrm{SiH}_{4} \rightarrow\left(\mathrm{SiH}_{3}\right)_{3} \mathrm{SiSiH}^{-}+\mathrm{H}_{2} \\
& (\mathrm{RC}):\left(\mathrm{SiH}_{3}\right)_{2} \mathrm{SiH}^{-}+\mathrm{SiH}_{4} \rightarrow\left(\mathrm{SiH}_{3}\right)_{3} \mathrm{Si}^{-}+\mathrm{H}_{2} \\
& (\mathrm{RD}):\left(\mathrm{SiH}_{3}\right)_{3} \mathrm{Si}^{-}+\mathrm{SiH}_{4} \rightarrow\left(\mathrm{SiH}_{3}\right)_{3} \mathrm{SiSiH}_{2}{ }^{-}+\mathrm{H}_{2}
\end{aligned}
$$

In the above reactions, the ground-state spin multiplicities for all the silylene anions (i.e., $\mathrm{SiH}_{3} \mathrm{SiHSiH}_{2}{ }^{-},\left(\mathrm{SiH}_{3}\right)_{2} \mathrm{SiHSiH}^{-}$and $\left.\left(\mathrm{SiH}_{3}\right)_{3} \mathrm{SiSiH}^{-}\right)$are doublet and for silyl anions (i.e., $\left(\mathrm{SiH}_{3}\right)_{2} \mathrm{SiH}^{-}$, $\left(\mathrm{SiH}_{3}\right)_{3} \mathrm{Si}^{-}$and $\left.\left(\mathrm{SiH}_{3}\right)_{3} \mathrm{SiSiH}_{2}{ }^{-}\right)$are singlet. The growth of $\left(\mathrm{SiH}_{3}\right)_{3} \mathrm{SiSiH}^{-}$starts from $\mathrm{SiH}_{3} \mathrm{SiHSiH}_{2}{ }^{-}$, which is produced during the initial polymerization reaction of $\mathrm{SiH}_{4}+\mathrm{Si}_{2} \mathrm{H}_{4}{ }^{-}$; $\left(\mathrm{SiH}_{3}\right)_{2} \mathrm{SiH}^{-}$, which leads to the formation of $\left(\mathrm{SiH}_{3}\right)_{3} \mathrm{SiSiH}_{2}{ }^{-}$, is generated by the reaction $\mathrm{SiH}_{4}+\mathrm{Si}_{2} \mathrm{H}_{5}{ }^{-}$.

Potential energy diagrams (relative Born-Oppenheimer potential energy $E$ in kcal $\mathrm{mol}^{-1}$ with respect to reactants) for reaction mechanisms of reactions RA-RD are shown in Fig. 2-5. The elementary steps involved and their classical energies of reaction $(\Delta E)$ are listed in Table 3. Energetic values are computed based on geometries optimized at M06-2X/MG3S and single point energies calculated with the same method. All the elementary reactions are bimolecular reactions except for the first step of $\mathrm{RB}$ and the third step of $\mathrm{RC}$, which are unimolecular isomerization reactions (intramolecular hydrogen transfer). We considered ion-dipole complex in four of the elementary bimolecular reactions, in which the barrier is negative: RA step 2, RB step 3, RC step 1, and RD step 1; the ion-dipole

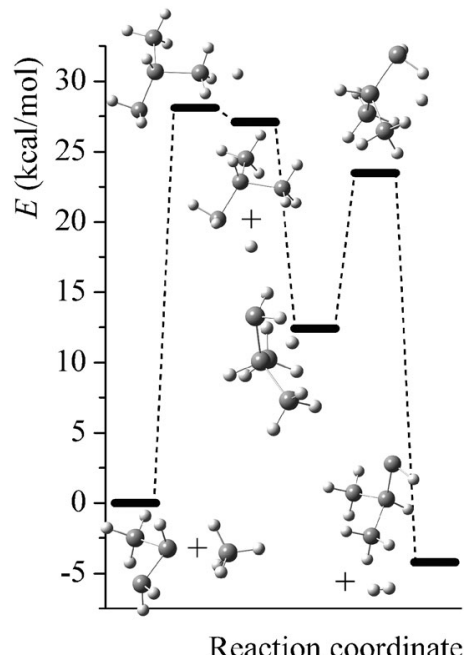

Fig. 2 Potential energy diagram for reaction mechanism of reaction RA; relative energies ( $E$ in $\mathrm{kcal} \mathrm{mol}^{-1}$, with respect to reactants $\mathrm{SiH}_{3} \mathrm{SiHSiH}_{2}{ }^{-}+$ $\mathrm{SiH}_{4}$ ) are computed at M06-2X/MG3S level.

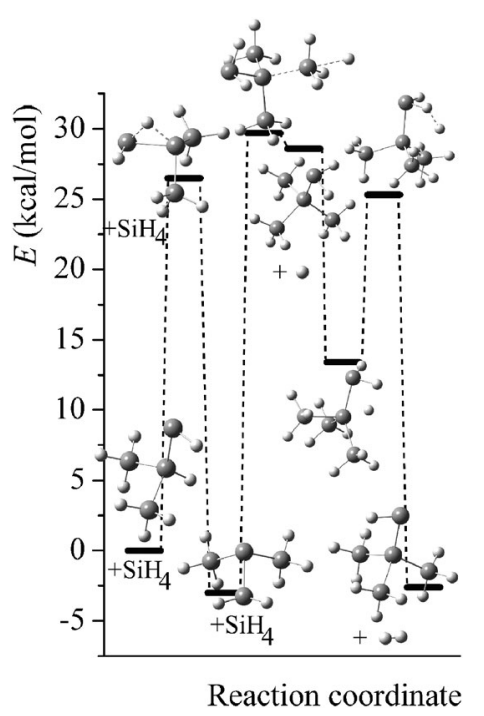

Fig. 3 Potential energy diagram for reaction mechanism of reaction RB; relative energies ( $E$ in $\mathrm{kcal} \mathrm{mol}^{-1}$, with respect to reactants $\left(\mathrm{SiH}_{3}\right)_{2} \mathrm{SiHSiH}^{-}+$ $\mathrm{SiH}_{4}$ ) are computed at M06-2X/MG3S level.

complex is used in computing tunneling transmission coefficient of the bimolecular reactions.

\subsection{Multi-structural and torsional potential anharmonicity}

Multi-structural and torsional potential anharmonicity factors of activation for the forward reactions are tabulated in Table 4, and for the reverse reactions are in ESI. $\dagger$ MS-T standard-state reaction enthalpy $\left(\Delta H_{\mathrm{rxn}}^{\circ}, \mathrm{MS}-\mathrm{T}\right.$ in $\left.\mathrm{kcal} \mathrm{mol}^{-1}\right)$ and reaction Gibbs free energy $\left(\Delta G_{\mathrm{rxn}}^{\circ}, \mathrm{MS}-\mathrm{T}\right.$ in $\left.\mathrm{kcal} \mathrm{mol}^{-1}\right)$ for all the reactions at $298 \mathrm{~K}$ and $1000 \mathrm{~K}$ are shown in Table 6 , and their values at various temperatures are tabulated in ESI. $\dagger$ The numbers of distinguishable conformers found in the conformational searches for the species that have multiple structures are given in ESI. $\dagger$ 


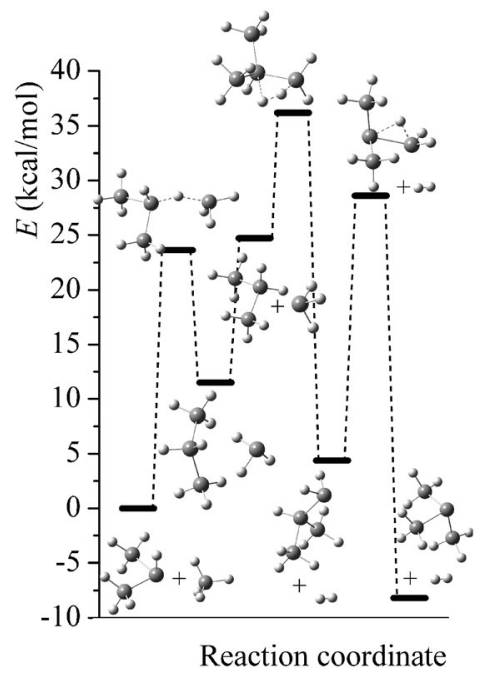

Fig. 4 Potential energy diagram for reaction mechanism of reaction RC; relative energies ( $E$ in $\mathrm{kcal} \mathrm{mol}^{-1}$, with respect to reactants $\left(\mathrm{SiH}_{3}\right)_{2} \mathrm{SiH}^{-}+$ $\mathrm{SiH}_{4}$ ) are computed at M06-2X/MG3S level.

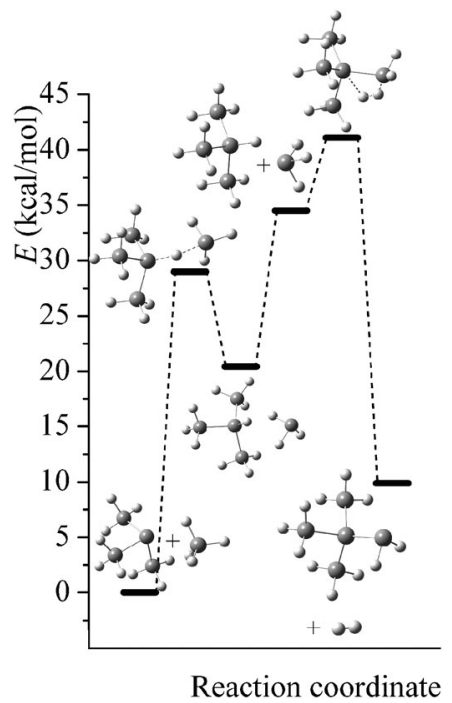

Fig. 5 Potential energy diagram for reaction mechanism of reaction RD; relative energies ( $E$ in kcal mol${ }^{-1}$, with respect to reactants $\left(\mathrm{SiH}_{3}\right)_{3} \mathrm{Si}^{-}+$ $\mathrm{SiH}_{4}$ ) are computed at M06-2X/MG3S level.

The errors for computing the thermal rate constants introduced by ignoring the multi-structural and torsional anharmonicity effects vary between different reactions and temperatures. For reactions $\mathrm{RA}$ step 1, RB step 3 and $\mathrm{RC}$ step 2, the errors are only slightly temperature dependent; the averaged errors (over 298-1500 K temperature range) for thermal rate constants computed without including MS-T effects for these reactions are respectively $32 \%, 43 \%$, and $44 \%$, with a standard deviation of $4 \%, 3 \%$, and $5 \%$ between various temperatures. For reaction $\mathrm{RB}$ step 1 , the $\mathrm{MS}$ - $\mathrm{T}$ effect can be ignored for temperatures below $800 \mathrm{~K}$, at which temperatures the errors are all smaller than $15 \%$; at $1500 \mathrm{~K}$, one would have an error of $42 \%$ in thermal rate constant if the MS-T factor were not included. For reaction RC step 1 at $1500 \mathrm{~K}$, the multistructural CVT/SCT rate constant is a factor of 5 smaller than the single-structural CVT/SCT rate constant; the ratio of the single-structural harmonic oscillator rovibrational partition function (SS-HO) to the MS-T rovibrational partition function is 0.138 for the TS and is 0.696 for the reactant $\left(\mathrm{SiH}_{3}\right)_{2} \mathrm{SiH}^{-}$, while the ratio of MS-HO partition function to SS-HO partition function is 2 for the TS and is 1 for $\left(\mathrm{SiH}_{3}\right)_{2} \mathrm{SiH}^{-}$, which indicates stronger couplings between torsional modes in the TS than in $\left(\mathrm{SiH}_{3}\right)_{2} \mathrm{SiH}^{-}$.

\subsection{High-pressure-limit thermal rate constants}

Calculated MS-CVT/SCT rate constants for all the forward reactions are listed in Table 5, and for reverse reactions in the ESI. $\dagger$ The following equations are used to fit the thermal rate constants: ${ }^{70,87}$

$$
k=\left\{\begin{array}{cl}
A\left(\frac{T}{300}\right)^{n} \exp \left[-\frac{E\left(T+T_{0}\right)}{R\left(T^{2}+T_{0}^{2}\right)}\right] & \text { endothermic reaction } \\
A\left(\frac{T+T_{0}}{300}\right)^{n} \exp \left[-\frac{E\left(T+T_{0}\right)}{R\left(T^{2}+T_{0}^{2}\right)}\right] & \text { exothermic reaction }
\end{array}\right.
$$

where $A, n, E$ and $T_{0}$ are fitting parameters, $T$ is temperature in Kelvin, and $R$ is the ideal gas constant $\left(1.9872 \times 10^{-3} \mathrm{kcal}\right.$ $\left.\mathrm{mol}^{-1} \mathrm{~K}^{-1}\right)$. Fitting parameters for forward reactions are shown in Table 6, and those for the reverse reactions are in the ESI. $\dagger$

Fig. 6 shows the computed small-curvature tunneling (SCT) transmission coefficients at various temperatures for the third step in reaction RC. At low temperature, the thermal rate constant can be increased by an order of magnitude due to

Table 3 Elementary steps in the proposed reaction mechanisms for reactions RA-RD, and their classical energies of reactions $\left(\mathrm{kcal}_{\mathrm{mol}}{ }^{-1}\right)$ at $\mathrm{M06}^{-2 \mathrm{X} / \mathrm{MG} \mathrm{S} \text { level }}$

\begin{tabular}{|c|c|c|c|}
\hline Reaction & Step & Chemical equation & $\Delta E\left(\mathrm{kcal} \mathrm{mol}^{-1}\right)$ \\
\hline A & 2 & $\left(\mathrm{SiH}_{3}\right)_{2} \mathrm{SiHSiH}_{2}^{-}+\mathrm{H} \rightarrow\left(\mathrm{SiH}_{3}\right)_{2} \mathrm{SiHSiH}^{-}+\mathrm{H}_{2}$ & -31.3 \\
\hline B & 1 & $\left(\mathrm{SiH}_{3}\right)_{2} \mathrm{SiHSiH}^{-} \rightarrow\left(\mathrm{SiH}_{3}\right)_{2} \mathrm{SiH}_{2} \mathrm{Si}^{-}$ & -3.0 \\
\hline B & 3 & $\left(\mathrm{SiH}_{3}\right)_{3} \mathrm{SiSiH}_{2}^{-}+\mathrm{H} \rightarrow\left(\mathrm{SiH}_{3}\right)_{3} \mathrm{SiSiH}^{-}+\mathrm{H}_{2}$ & -31.2 \\
\hline $\mathrm{C}$ & 1 & $\left(\mathrm{SiH}_{3}\right)_{2} \mathrm{SiH}^{-}+\mathrm{SiH}_{4} \rightarrow\left(\mathrm{SiH}_{3}\right)_{2} \mathrm{SiH}_{2}+\mathrm{SiH}_{3}^{-}$ & 24.7 \\
\hline $\mathrm{C}$ & 2 & $\left(\mathrm{SiH}_{3}\right)_{2} \mathrm{SiH}_{2}+\mathrm{SiH}_{3}^{-} \rightarrow\left(\mathrm{SiH}_{3}\right)_{2} \mathrm{SiHSiH}_{2}^{-}+\mathrm{H}_{2}$ & -20.3 \\
\hline $\mathrm{D}$ & 2 & $\left(\mathrm{SiH}_{3}\right)_{3} \mathrm{SiH}+\mathrm{SiH}_{3}^{-} \rightarrow\left(\mathrm{SiH}_{3}\right)_{3} \mathrm{SiSiH}_{2}^{-}+\mathrm{H}_{2}$ & -24.6 \\
\hline
\end{tabular}


Table 4 MS-T factors for activation at various temperatures for forward reactions computed at M06-2X/MG3S level

\begin{tabular}{|c|c|c|c|c|c|c|c|c|c|c|}
\hline \multirow[b]{2}{*}{$T / \mathrm{K}$} & \multicolumn{2}{|l|}{ RA } & \multicolumn{3}{|l|}{$\mathrm{RB}$} & \multicolumn{3}{|l|}{$\mathrm{RC}$} & \multicolumn{2}{|l|}{$\mathrm{RD}$} \\
\hline & Step 1 & Step 2 & Step 1 & Step 2 & Step 3 & Step 1 & Step 2 & Step 3 & Step 1 & Step 2 \\
\hline 298 & 1.41 & 0.57 & 0.93 & 1.91 & 1.68 & 0.52 & 1.64 & 0.75 & 0.70 & 0.52 \\
\hline 300 & 1.41 & 0.57 & 0.93 & 1.90 & 1.68 & 0.52 & 1.64 & 0.75 & 0.70 & 0.52 \\
\hline 400 & 1.50 & 0.61 & 0.92 & 1.70 & 1.69 & 0.47 & 1.65 & 0.82 & 0.66 & 0.57 \\
\hline 500 & 1.55 & 0.66 & 0.96 & 1.52 & 1.72 & 0.42 & 1.68 & 0.91 & 0.62 & 0.61 \\
\hline 600 & 1.56 & 0.70 & 1.02 & 1.36 & 1.74 & 0.38 & 1.72 & 1.02 & 0.58 & 0.66 \\
\hline 700 & 1.55 & 0.75 & 1.09 & 1.24 & 1.77 & 0.35 & 1.76 & 1.13 & 0.55 & 0.70 \\
\hline 800 & 1.53 & 0.80 & 1.17 & 1.13 & 1.80 & 0.32 & 1.82 & 1.25 & 0.52 & 0.74 \\
\hline 900 & 1.50 & 0.85 & 1.25 & 1.05 & 1.82 & 0.29 & 1.87 & 1.37 & 0.49 & 0.78 \\
\hline 1000 & 1.47 & 0.90 & 1.33 & 0.98 & 1.84 & 0.27 & 1.92 & 1.48 & 0.46 & 0.82 \\
\hline 1500 & 1.31 & 1.13 & 1.71 & 0.74 & 1.95 & 0.20 & 2.17 & 2.03 & 0.36 & 1.00 \\
\hline
\end{tabular}

Table 5 MS-CVT/SCT rate constants for forward reactions computed at M06-2X/MG3S level at various temperatures. For bimolecular reactions, units of rate constants are $\mathrm{cm}^{3}$ molecule $\mathrm{e}^{-1} \mathrm{~s}^{-1}$; for unimolecular reactions, units are $\mathrm{s}^{-1}$

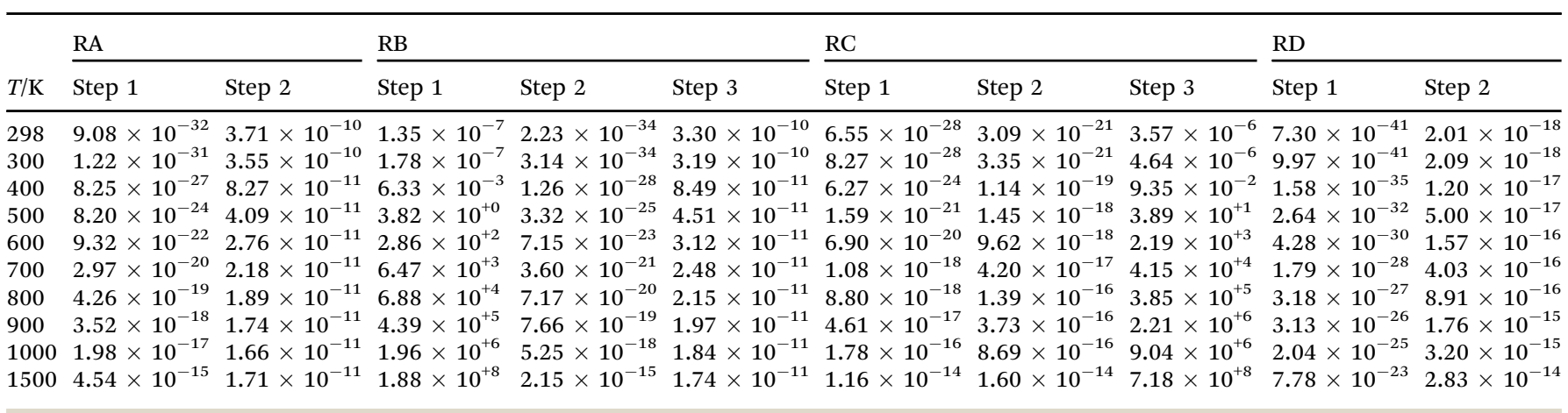

quantum tunneling. The SCT tunneling transmission coefficient decays rapidly as temperature increases; $\kappa^{\text {SCT }}$ decreases from 11.1 at $298 \mathrm{~K}$ to 2.0 at $500 \mathrm{~K}$, and to 1.1 at $1500 \mathrm{~K}$.

\subsection{High-pressure-limit activation energy}

The Arrhenius activation energies are defined by

$$
E_{\mathrm{a}}=-R \frac{\mathrm{d}(\ln k)}{\mathrm{d}(1 / T)}
$$

and are obtained by putting eqn (21) into eqn (22), which yields

$$
E_{\mathrm{a}}=\left\{\begin{array}{cl}
\frac{E\left(T^{4}+2 T_{0} T^{3}-T_{0}^{2} T^{2}\right)}{\left(T^{2}+T_{0}^{2}\right)^{2}}+n R T & \text { endothermic reaction } \\
\frac{E\left(T^{4}+2 T_{0} T^{3}-T_{0}^{2} T^{2}\right)}{\left(T^{2}+T_{0}^{2}\right)^{2}}+\frac{n R T^{2}}{T+T_{0}} & \text { exothermic reaction }
\end{array}\right.
$$

Computed activation energies for both forward and reverse reactions are shown in ESI. $\dagger$ The temperature dependence of activation energies of forward reactions is depicted in Fig. 7.

Table 6 Fitting parameters for MS-CVT/SCT rate constants for forward reactions computed by M06-2X/MG3S and MS-T reaction enthalpy and reaction

\begin{tabular}{|c|c|c|c|c|c|c|c|c|c|c|}
\hline$\Delta H_{\mathrm{rxn}, 0}^{\circ}$ & Endo & Exo & Exo & Endo & Exo & Endo & Exo & Exo & Endo & Exo \\
\hline $\ln A$ & -33.986 & -29.040 & 21.176 & -33.713 & -28.1662 & -31.596 & -38.010 & 24.442 & -52.742 & -38.301 \\
\hline$n$ & 4.7020 & 1.8197 & 2.7059 & 4.7496 & 1.3979 & 3.0955 & 4.8766 & 1.9478 & 5.4789 & 4.6543 \\
\hline$T_{0}$ & 110.23 & 50.00 & 107.81 & 99.92 & 42.27 & 114.19 & 186.33 & 10.00 & 104.93 & 255.65 \\
\hline$\Delta H_{\mathrm{rxn}, 1000 \mathrm{~K}}^{\circ}$ & 26.9 & -30.3 & -2.4 & 33.3 & -33.2 & 24.3 & -19.3 & -12.2 & 33.7 & -20.9 \\
\hline$\Delta G_{\mathrm{rxn}, 298 \mathrm{~K}}^{\circ}$ & 25.7 & -30.5 & -2.1 & 29.6 & -30.6 & 23.5 & -21.0 & -10.9 & 32.2 & -24.8 \\
\hline$\Delta G_{\mathrm{rxn}, 1000 \mathrm{~K}}^{\circ}$ & 27.0 & -32.7 & -0.5 & 29.4 & -31.5 & 21.9 & -22.6 & -8.2 & 29.1 & -26.6 \\
\hline
\end{tabular}
Gibbs free energy at $298 \mathrm{~K}$ and $1000 \mathrm{~K}^{a}$

${ }^{a}$ The standard-state pressure is one bar. For bimolecular (bimol) reactions, the units of parameter $A$ are $\mathrm{cm}^{3}$ molecule ${ }^{-1} \mathrm{~s}^{-1}$; for unimolecular (unimol) reactions, the unit is $\mathrm{s}^{-1}$. The parameters $T_{0}$ and $E$ are in units of $\mathrm{K}$ and kcal mol ${ }^{-1}$ respectively, and $n$ is unitless; enthalpy and free energy are in units of $\mathrm{kcal} \mathrm{mol}^{-1}$. Reactions that are endothermic (endo) at $0 \mathrm{~K}$ are fit using eqn (21), and those that are exothermic (exo) at $0 \mathrm{~K}$ are fit using eqn (21). 


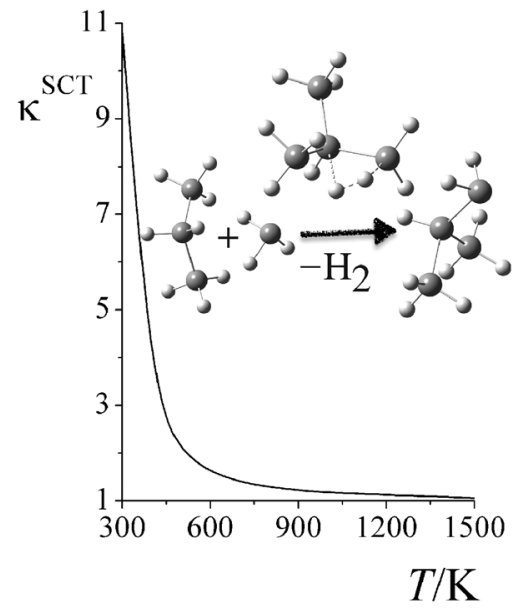

Fig. 6 Small-curvature tunneling (SCT) transmission coefficient of reaction RC step 2 at various temperatures.

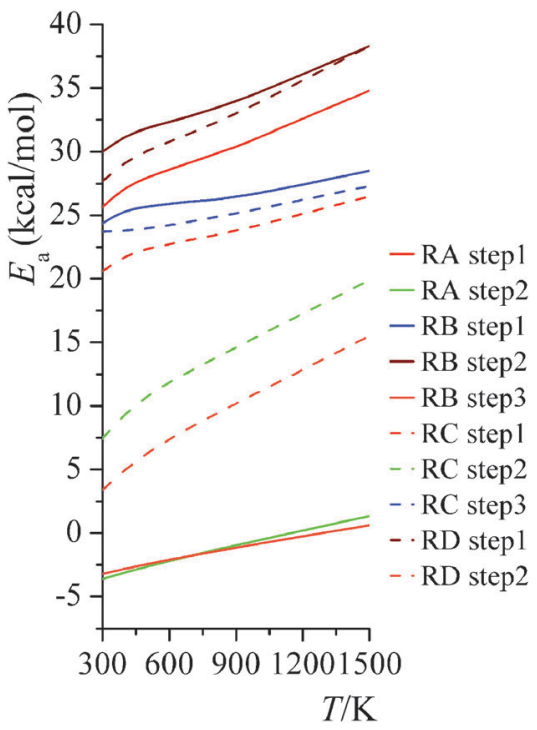

Fig. 7 High-pressure-limit activation energies for forward reactions at various temperatures.

The temperature dependence of activation energy computed based on MS-CVT/SCT rate constants could be quite different from the one computed from conventional transition state theory (TST), because of the effects of tunneling, recrossing, and multi-structural torsional anharmonicity. For instance, in step 2 of reaction RC, the MS-CVT/SCT activation energy is $7.4 \mathrm{kcal} \mathrm{mol}^{-1}$ at $298 \mathrm{~K}$, and it increases by $12.5 \mathrm{kcal} \mathrm{mol}^{-1}$ from $298 \mathrm{~K}$ to $1500 \mathrm{~K}$; the conventional single-structural TST (without tunneling) activation energy at $298 \mathrm{~K}$ is $10.9 \mathrm{kcal} \mathrm{mol}^{-1}$, which is $3.5 \mathrm{kcal} \mathrm{mol}^{-1}$ higher than MS-CVT/SCT activation energy at $298 \mathrm{~K}$. We also plot the SS-TST, SS-TST/SCT, MS-CVT, and MS-CVT/SCT rate constant for RC step 2 at various temperatures in Fig. 8. The SS-TST/SCT natural logarithm rate constant curve decreases slower than the straight-line-shape of SS-TST curve as $1000 \mathrm{~K} / T$ increases; at high temperature, tunneling is negligible and SS-TST overlaps with SS-TST/SCT curve, while at

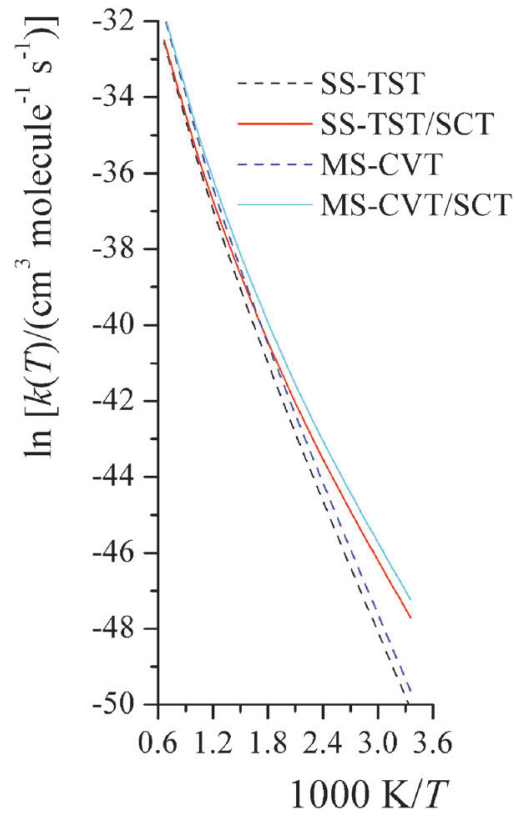

Fig. 8 The computed high-pressure-limit SS-TST, SS-TST/SCT, MS-CVT, and MS-CVT/SCT bimolecular thermal rate constants $\left(\mathrm{cm}^{3}\right.$ molecule $\left.{ }^{-1} \mathrm{~s}^{-1}\right)$ for reaction RC step 2 at various temperatures (K).

low temperature, SS-TST curve is significantly lower than SS-TST/SCT curve. The MS-CVT/SCT curve differs negligibly from the SS-CVT/SCT curve due to the small MS-T effect.

\subsection{Falloff effects for unimolecular isomerization reactions}

Step 1 of reaction RB and step 3 of reaction RC are unimolecular isomerization reactions. The predicted falloff curves for these two reactions at various temperatures (in $\mathrm{K}$ ) and pressures

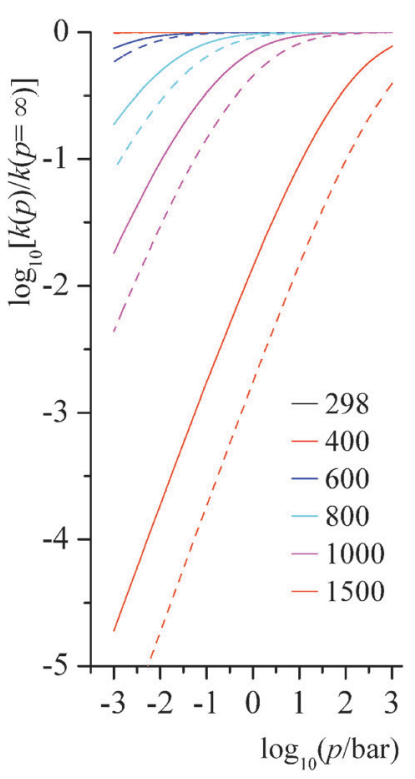

Fig. 9 Predicted falloff curves for thermal rate constants of unimolecular isomerization reactions at various temperatures $(K)$ and pressures (bar). Solid lines are for reaction RB step 1; dashed lines are for reaction RC step 3. 
(in bar) are shown in Fig. 9. Falloff curves are plotted as $\log _{10}[k(p) / k(p=\infty)]$ versus pressure, where $k(p)$ is the thermal unimolecular rate constant at pressure $p$, and $k(p=\infty)$ is the high-pressure-limit rate constant computed by MS-CVT/SCT theory. The falloff curves for pressures from $10^{-5}$ to 1 bar are shown in ESI. $\dagger$

At low and middle temperatures $(T<600 \mathrm{~K})$, falloff effects for these two unimolecular reactions are negligible. At $600 \mathrm{~K}$, the rate constant of RB step 1 at 1000 bar is $2.83 \times 10^{2} \mathrm{~s}^{-1}$, and at 0.01 bar it is $2.66 \times 10^{2} \mathrm{~s}^{-1}$; the rate constant of RC step 3 at $600 \mathrm{~K}$ and 1000 bar is $2.19 \times 10^{3} \mathrm{~s}^{-1}$, while at the same temperature at 0.01 bar it is $1.90 \times 10^{3} \mathrm{~s}^{-1}$. For RB step 1 , the collision efficiency coefficient $\beta_{\mathrm{c}}$ at $298 \mathrm{~K}, 600 \mathrm{~K}$, and $1000 \mathrm{~K}$ are $0.34,0.14$ and 0.03 , respectively; and for RC step 3 , collision efficiency coefficients at $298 \mathrm{~K}, 600 \mathrm{~K}$, and $1000 \mathrm{~K}$ are $0.33,0.12$ and 0.02 , respectively.

At high temperature, falloff effects become more significant. At $1500 \mathrm{~K}$, the rate constant of RB step 1 is $1.45 \times 10^{8} \mathrm{~s}^{-1}$ at 1000 bar and is $2.66 \times 10^{6} \mathrm{~s}^{-1}$ at $1.0 \mathrm{bar}$, so the 1 bar result is a factor of 0.014 smaller than the high-pressure-limit. The rate constant of RC step 3 at $1500 \mathrm{~K}$ is $2.82 \times 10^{8} \mathrm{~s}^{-1}$ at 1000 bar and is $1.25 \times 10^{6} \mathrm{~s}^{-1}$ at 1 bar, so the high-pressure-limit rate constant is 574 times larger than the one at 1.0 bar.

\subsection{Pressure-dependent activation energy}

The activation energies for the unimolecular isomerization reactions RB step 1 and RC step 3 depend on both temperature and pressure. We show the pressure-dependent activation energies at $600 \mathrm{~K}, 800 \mathrm{~K}$, and $1000 \mathrm{~K}$ in Fig. 10. At the highest pressures shown $\left(10^{3} \mathrm{bar}\right)$, the activation energies are at the high-pressure limit. At $600 \mathrm{~K}$ and around $0.1 \mathrm{bar}$, where falloff effects on the rate become notable, the activation energies also start falling as the pressures decreases. At $800 \mathrm{~K}$ and $1000 \mathrm{~K}$, the activation energy is significantly pressure dependent; the

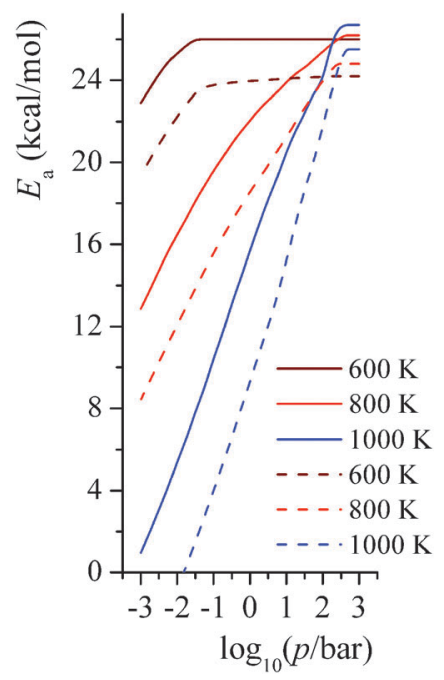

Fig. 10 Predicted pressure-dependent activation energies ( $\mathrm{kcal} \mathrm{mol}^{-1}$ ) for unimolecular isomerization reactions RB step 1 and RC step 3 at $600 \mathrm{~K}$, $800 \mathrm{~K}$, and $1000 \mathrm{~K}$. Solid lines are for reaction RB step 1; dashed lines are for reaction $\mathrm{RC}$ step 3. activation energy decreases almost linearly with respect to the pressure. At the transition pressure $p_{1 / 2},{ }^{25}$ which is defined as the pressure at which the unimolecular rate constant is half of the high-pressure-limit value, the ratio of $E_{\mathrm{a}}\left(p=p_{1 / 2}\right)$ to $E_{\mathrm{a}}(p=\infty)$ is 0.6 for $\mathrm{RB}$ step $1\left(p_{1 / 2}=0.01 \mathrm{bar}\right)$ and 0.6 for RC step $3\left(p_{1 / 2}=0.03 \mathrm{bar}\right)$ at $800 \mathrm{~K}$, and it is 0.5 for RB step 1 $\left(p_{1 / 2}=0.3 \mathrm{bar}\right)$ and 0.4 for RC step $3\left(p_{1 / 2}=1 \mathrm{bar}\right)$ at $1000 \mathrm{~K}$.

\section{Summary}

In the current work, we tested various exchange-correlation density functionals for an important system in nanodusty plasmas, in particular silylene and silyl anions reacting with silane molecules. Among the functionals we tested in this work, M06-2X is the most successful hybrid functional and MN15-L is the most successful local functional. Reaction mechanisms for the growth of silicon hydride clusters have been proposed, and the thermal rate constants of the elementary reactions involved in the reaction mechanisms were computed using multi-structural canonical variational transition state theory with the small-curvature tunneling approximation. Two unimolecular isomerization reactions are involved in the reaction mechanism, and their pressure dependent thermal rate constants were estimated based on system-specific quantum RRK (SS-QRRK) theory combined with Lindemann-Hinshelwood theory.

This work provides guidance for choosing density functionals for studying anion-neutral reactions in the silane-based reactive plasma. The methodology for computing thermal rate constants, whose values are rarely available experimentally, is also useful in estimating input kinetic data in plasma modeling for engineering applications. The extension of the SS-QRRK method to unimolecular isomerizations is also of more general use; it may be applied, for example, to atmospheric chemistry and combustion chemistry.

\section{Acknowledgements}

The authors appreciate helpful discussion with Steven L. Girshick and Mark J. Kushner and valuable contributions from Prasenjit Seal. This work is supported by the National Science Foundation under award no. CHE11-24752.

\section{References}

1 U. V. Bhandarkar, M. T. Swihart, S. L. Girshick and U. R. Kortshagen, J. Phys. D: Appl. Phys., 2000, 33, 2731.

2 U. V. Bhandarkar, U. R. Kortshagen and S. L. Girshick, J. Phys. D: Appl. Phys., 2003, 36, 1399.

3 S. J. Warthesen and S. L. Girshick, Plasma Chem. Plasma Process., 2007, 27, 292.

4 P. Agarwal and S. L. Girshick, Plasma Sources Sci. Technol., 2012, 21, 055023.

5 A. Gallagher, Phys. Rev. E: Stat. Phys., Plasmas, Fluids, Relat. Interdiscip. Top., 2000, 62, 2690.

6 L. Ravi and S. L. Girshick, Phys. Rev. E: Stat., Nonlinear, Soft Matter Phys., 2009, 79, 026408. 
7 S. Nunomura, I. Yoshida and M. Kondo, Appl. Phys. Lett., 2009, 94, 071502.

8 P. Agarwal and S. L. Girshick, Plasma Chem. Plasma Process., 2014, 34, 489.

9 R. V. de Vijver, N. M. Vandewiele, P. L. Bhoorasingh, B. L. Slakman, F. S. Khanshan, H.-H. Carstensen, M.-F. Reyniers, G. B. Marin, R. H. West and K. M. Van Geem, Int. J. Chem. Kinet., 2015, 47, 199.

10 J. L. Bao, P. Seal and D. G. Truhlar, Phys. Chem. Chem. Phys., 2015, 17, 15928.

11 J. L. Bao, J. Zheng and D. G. Truhlar, J. Am. Chem. Soc., 2016, 138, 2690.

12 T. Yu, J. Zheng and D. G. Truhlar, Chem. Sci., 2011, 2, 2199.

13 B. C. Garrett and D. G. Truhlar, J. Chem. Phys., 1979, 70, 1593.

14 B. C. Garrett and D. G. Truhlar, Acc. Chem. Res., 1980, 13, 440.

15 D. G. Truhlar, A. D. Isaacson and B. C. Garrett, in Theory of Chemical Reaction Dynamics, ed. M. Baer, CRC Press, Boca Raton, 1985, pp. 65-137.

16 J. L. Bao, R. Meana-Pañeda and D. G. Truhlar, Chem. Sci., 2015, 6, 5866.

17 J. L. Bao, P. Sripa and D. G. Truhlar, Phys. Chem. Chem. Phys., 2016, 18, 1032.

18 J. Zheng and D. G. Truhlar, J. Chem. Theory Comput., 2013, 9, 1356.

19 A. Fernández-Ramos, B. A. Ellingson, R. Meana-Pañeda, J. MC Marques and D. G. Truhlar, Theor. Chem. Acc., 2007, 118, 813.

20 N. M. Vandewiele, R. V. de Vijver, K. M. Van Geem, M.-F. Reyniers and G. B. Marin, J. Comput. Chem., 2015, 36, 181.

21 (a) H.-H. Carstensen and A. M. Dean, Compr. Chem. Kinet., 2007, 42, 101; (b) J. W. Bozzelli, A. Y. Chang and A. M. Dean, Int. J. Chem. Kinet., 1997, 29, 161; (c) A. Y. Chang, J. W. Bozzelli and A. M. Dean, Z. Phys. Chem., 2000, 214, 1533.

22 J. Troe, J. Chem. Phys., 1977, 66, 4745.

23 J. Troe, J. Chem. Phys., 1977, 66, 4758.

24 K. J. Laidler, Chemical Kinetics, McGraw-Hill, New York, 2nd edn, 1965, p. 145.

25 K. A. Holbrook, M. J. Pilling and S. H. Robertson, Unimolecular Reactions, John Wiley \& Sons, New York, 2nd edn, 1996, ch. 2.

26 T. Baer and W. L. Hase, Unimolecular Reaction Dynamics, Oxford University Press, New York, 1996, p. 5.

27 A. M. Dean, J. Phys. Chem., 1985, 89, 4600.

28 Y. Zhao and D. G. Truhlar, J. Chem. Theory Comput., 2008, 4, 1849.

29 B. J. Lynch, Y. Zhao and D. G. Truhlar, J. Phys. Chem. A, 2003, 107, 1384.

30 R. Krishnan, J. S. Binkley, R. Seeger and J. Pople, J. Chem. Phys., 1980, 72, 650.

31 T. Clark, J. Chandrasekhar, G. W. Spitznagel and P. Schleyer, J. Comput. Chem., 1983, 4, 294.

32 M. J. Frisch, J. A. Pople and J. S. Binkley, J. Chem. Phys., 1984, 80, 3265.

33 V. I. Lebedev and L. Skorokhodov, Russ. Acad. Sci. Dokl. Math., 1992, 45, 587.
34 M. J. Frisch, G. W. Trucks, H. B. Schlegel, G. E. Scuseria, M. A. Robb, J. R. Cheeseman, G. Scalmani, V. Barone, B. Mennucci, G. A. Petersson, H. Nakatsuji, M. Caricato, X. Li, H. P. Hratchian, A. F. Izmaylov, J. Bloino, G. Zheng, J. L. Sonnenberg, M. Hada, M. Ehara, K. Toyota, R. Fukuda, J. Hasegawa, M. Ishida, T. Nakajima, Y. Honda, O. Kitao, H. Nakai, T. Vreven, J. A. Montgomery, Jr., J. E. Peralta, F. Ogliaro, M. Bearpark, J. J. Heyd, E. Brothers, K. N. Kudin, V. N. Staroverov, R. Kobayashi, J. Normand, K. Raghavachari, A. Rendell, J. C. Burant, S. S. Iyengar, J. Tomasi, M. Cossi, N. Rega, J. M. Millam, M. Klene, J. E. Knox, J. B. Cross, V. Bakken, C. Adamo, J. Jaramillo, R. Gomperts, R. E. Stratmann, O. Yazyev, A. J. Austin, R. Cammi, C. Pomelli, J. Ochterski, R. L. Martin, K. Morokuma, V. G. Zakrzewski, G. A. Voth, P. Salvador, J. J. Dannenberg, S. Dapprich, A. D. Daniels, O. Farkas, J. B. Foresman, J. V. Ortiz, J. Cioslowski and D. J. Fox, Gaussian 09 (Revision D. 01), Gaussian, Inc., Wallingford, CT, 2009.

35 Y. Zhao, R. Peverati, K. Yang, H. Xiao, H. Yu and D. G. Truhlar, MN-GFM version 6.5 computer program module, University of Minnesota, Minneapolis, 2015.

36 E. Papajak and D. G. Truhlar, J. Chem. Phys., 2012, 137, 064110.

37 E. Papajak and D. G. Truhlar, J. Chem. Theory Comput., 2010, 6, 597.

38 R. Peverati and D. G. Truhlar, J. Phys. Chem. Lett., 2012, 3, 117.

39 R. Peverati and D. G. Truhlar, Phys. Chem. Chem. Phys., 2012, 14, 13171.

40 H. S. Yu, H. Xiao and D. G. Truhlar, J. Chem. Theory Comput., 2016, 12, 1280.

41 P. J. Stephens, F. J. Devlin, C. F. Chabalowski and M. J. Frisch, J. Phys. Chem., 1994, 98, 11623.

42 C. Adamo and V. Barone, J. Chem. Phys., 1999, 110, 6158.

43 V. N. Staroverov, G. E. Scuseria, J. Tao and J. P. Perdew, J. Chem. Phys., 2003, 119, 12129.

44 J. Sun, R. Haunschild, B. Xiao, I. W. Bulik, G. E. Scuseria and J. P. Perdew, J. Chem. Phys., 2013, 138, 044113.

45 B. J. Lynch, P. L. Fast, M. Harris and D. G. Truhlar, J. Phys. Chem. A, 2000, 104, 4811.

46 Y. Zhao, N. E. Schultz and D. G. Truhlar, J. Chem. Phys., 2005, 123, 161103.

47 Y. Zhao and D. G. Truhlar, Theor. Chem. Acc., 2008, 120, 215. 48 Y. Zhao, N. E. Schultz and D. G. Truhlar, J. Chem. Theory Comput., 2006, 2, 364.

49 R. Peverati and D. G. Truhlar, J. Phys. Chem. Lett., 2011, 2, 2810.

50 R. Peverati and D. G. Truhlar, Phys. Chem. Chem. Phys., 2012, 14, 16187.

51 R. Peverati and D. G. Truhlar, J. Chem. Phys., 2011, 135, 191102.

52 T. W. Keal and D. J. Tozer, J. Chem. Phys., 2005, 123, 121103.

53 A. V. Krukau, O. A. Vydrov, A. F. Izmaylov and G. E. Scuseria, J. Chem. Phys., 2006, 125, 224106.

54 A. D. Boese and N. C. Handy, J. Chem. Phys., 2002, 116, 9559. 
55 J. D. Chai and M. Head-Gordon, Phys. Chem. Chem. Phys., 2008, 10, 6615.

56 J. A. Pople, M. Head-Gordon and K. Raghavachari, J. Chem. Phys., 1987, 87, 5968.

57 Y. Zhao and D. G. Truhlar, J. Phys. Chem. A, 2005, 109, 6624.

58 T. H. Dunning, J. Chem. Phys., 1989, 90, 1007.

59 M. Head-Gordon, J. A. Pople and M. J. Frisch, Chem. Phys. Lett., 1988, 153, 503.

60 D. G. Truhlar, Chem. Phys. Lett., 1998, 294, 45.

61 A. Karton and J. M. L. Martin, Theor. Chem. Acc., 2006, 115, 330 .

62 A. Halkier, T. Helgaker, P. Jørgensen, W. Klopper, H. Koch, O. Jeppe and A. K. Wilson, Chem. Phys. Lett., 1998, 286, 243.

63 Y. Zhao, H. T. Ng, R. Peverati and D. G. Truhlar, J. Chem. Theory Comput., 2012, 8, 2824.

64 J. L. Bao, H. S. Yu, K. Duanmu, M. A. Makeev, X. Xu and D. G. Truhlar, ACS Catal., 2015, 5, 2070.

65 K. A. Nguyen, C. F. Jackels and D. G. Truhlar, J. Chem. Phys., 1996, 104, 6491.

66 C. F. Jackels, Z. Gu and D. G. Truhlar, J. Chem. Phys., 1995, $102,3188$.

67 T. Joseph, R. Steckler and D. G. Truhlar, J. Chem. Phys, 1987, 87, 7036.

68 J. Villà and D. G. Truhlar, Theor. Chem. Acc., 1997, 97, 317.

69 I. M. Alecu, J. Zheng, Y. Zhao and D. G. Truhlar, J. Chem. Theory Comput., 2010, 6, 2872.

70 J. Zheng and D. G. Truhlar, Faraday Discuss., 2012, 157, 59.

71 J. Zheng and D. G. Truhlar, J. Chem. Theory Comput., 2013, 9, 2875.

72 J. Zheng, S. L. Mielke, K. L. Clarkson and D. G. Truhlar, MSTor computer program, version 2011, University of Minnesota, Minneapolis, MN, 2011.
73 J. Zheng, S. Zhang, B. J. Lynch, J. C. Corchado, Y.-Y. Chuang, P. L. Fast, W.-P. Hu, Y.-P. Liu, G. C. Lynch, K. A. Nguyen, C. F. Jackels, A. F. Ramos, B. A. Ellingson, V. S. Melissas, J. Vill_a, I. Rossi, E. L. Coitino, J. Pu, T. V. Albu, R. Steckler, B. C. Garrett, A. D. Isaacson and D. G. Truhlar, POLYRATE, version 2010-A, University of Minnesota, Minneapolis, 2010.

74 J. Zheng, S. Zhang, J. C. Corchado, Y. Y. Chuang, E. L. Coitino, B. A. Ellingson and D. G. Truhlar, GAUSSRATE, version 2009-A, University of Minnesota, Minneapolis, 2010. 75 Y. Shi, Acc. Chem. Res., 2015, 48, 163.

76 A. Rahman, Phys. Rev., 1964, 136, A405.

77 M. J. Kushner, J. Appl. Phys., 1988, 63, 2532.

78 A. Dollet, S. de Persisb and F. Teyssandier, Phys. Chem. Chem. Phys., 2004, 6, 1203.

79 (a) A. W. Jasper, J. A. Miller and S. J. Klippenstein, J. Phys. Chem. A, 2013, 117, 12243; (b) A. W. Jasper, K. M. Pelzer, J. A. Miller, E. Kamarchik, L. B. Harding and S. J. Klippenstein, Science, 2014, 346, 1212.

80 J. Troe, J. Phys. Chem., 1979, 83, 114.

81 K. R. Yang, A. Jalan, W. H. Green and D. G. Truhlar, J. Chem. Theory Comput., 2013, 9, 418.

82 X. Xu, W. Zhang, M. Tang and D. G. Truhlar, J. Chem. Theory Comput., 2015, 11, 2036.

83 T. J. Lee and P. R. Taylor, Int. J. Quantum Chem., Symp., 1989, 23, 199.

84 J. C. Rienstra-Kiracofe, W. D. Allen and H. F. Schaefer, J. Phys. Chem. A, 2000, 104, 9823.

85 M. Martinez-Avila and J. Peiro-Garcia, J. Phys. Chem. Solids, Lett. Sect., 2003, 370, 313.

86 N. Lambert, N. Kaltsoyannis, S. D. Price, J. Zabka and Z. Herman, J. Phys. Chem. A, 2006, 110, 2898.

87 J. Zheng and D. G. Truhlar, Phys. Chem. Chem. Phys., 2010, 12, 7782 . 